\title{
Numerical analysis of concrete piles driving in saturated dense and loose sand deposits
}

\author{
M. Aghayarzadeh, H. Khabbaz \& B. Fatahi \\ University of Technology Sydney (UTS), Sydney, NSW, Australia
}

\begin{abstract}
Many approaches and techniques are used to evaluate pile axial capacity ranging from static methods to dynamic methods, which are based on either the results of pile driving or numerical simulations, which require reliable constitutive models representing the real soil behaviour and the interaction between the pile and soil. In this paper, using PLAXIS software and different constitutive soil models including MohrCoulomb, Hardening Soil and Hypoplastic with Intergranular Strain models, the behaviour of concrete piles driven into saturated dense and loose sand deposits under a hammer blow is evaluated. The main objective of this study is to assess the influence of different factors including frequency of loading and Hypoplastic soil model parameters on the recorded velocity and pile head displacement. In addition, the concept of one-dimensional wave propagation induced by pile driving is discussed. It is indicated that using the Intergranular Strain concept, defined in Hypoplastic soil model, small strain behaviour of soil around the pile during driving can directly be captured. The results of this study reveals that considering the Hypoplastic model, incorporating the Intergranular Strain concept, can accumulate much less strains than the corresponding predictions excluding the Intergranular Strain, and hence predict the pile performance during driving more realistically.
\end{abstract}

\section{INTRODUCTION}

Despite the fact that pile design methods have considerably advanced within the past few years, the most fundamental aspect of pile design related to the axial bearing capacity, still heavily relies on empirical correlations. Many studies have been reported during the last decades to improve the prediction of pile axial and lateral capacity, as well as adopting dynamic methods during pile driving and testing for pile evaluation (Goble et al. 1967, Goble \& Rausche 1970, Rausche et al. 1972, Fakharian \& Hosseinzadeh 2011, Fatahi et al. 2014). In fact, pile head displacements, force and velocity traces, which are captured during pile driving and dynamic load testing, are used as the benchmarks of pile performance. Hence, the bearing capacity of a pile can be calculated by analysing these data, applying direct and indirect methods used in the pile driving analyser (PDA) device and CAPWAP software, respectively.

Some of the previous research studies tried to use the finite element method to analyse pile driving. Mabsout \& Tassoulas (1994) and Mabsout et al. (1995) assumed a bored pile for the pile driving analysis with embedment depths of 6,12 and $18 \mathrm{~m}$, which were surrounded by saturated normally-consolidated clay. They employed a non-linear bounding surfaceplasticity model with the aim of conducting a detailed analysis of pile driving, using a finite element technique by taking into account the non-linear behaviour of undrained clayey soil and tracing the penetration of the pile into the soil. Fakharian et al. (2014) simulated the signal matching process during dynamic load testing, using finite element and finite difference software packages in which Mohr-Coulomb soil model was assigned to the soil layers. In the latter study, the pile load testing procedure was simulated in more realistic conditions, so it was concluded that incorporating the radiation damping effect could results in more reasonable predictions. It should be noted that application of advanced soil models and consideration of nonlinear soil-pile interaction have been considered widely in other fields such as geotechnical earthquake engineering (e.g. Hokmabadi \& Fatahi 2016, Fatahi et al. 2018 ).

In this study, using PLAXIS 2D version 2017, concrete pile performance, dynamically driven into saturated loose and dense sand has been scrutinised. In the analysis, the recorded force and velocity at the gauge location and the pile head displacement under a single hammer blow at the end of driving have been assessed, using different soil models ranging from Mohr-Coulomb to advanced soil models. The results, 
predicted through various soil models have been evaluated and compared. It should be noted that, the small strain behaviour of soil around the pile, which is observed during pile driving, has been assessed using an advanced soil model as a part of this study.

\section{NUMERICAL MODEL CHARACTERISTICS}

In this study, the axisymmetric finite element model was used in numerical simulation. Concrete pile as a volume pile element with a diameter of $0.4 \mathrm{~m}$ and a total length of $10 \mathrm{~m}$ was modelled numerically. A linear elastic model with an elastic modulus of $300 \mathrm{GPa}$, a Poisson's ratio of 0.2 and a unit weight of $25 \mathrm{kN} / \mathrm{m}^{3}$ was assigned to the pile cluster. Whereas, elastic perfectly plastic Mohr-Coulomb (MC), Hardening Soil (HS) and Hypoplastic (HP) with Intergranular Strain (IGS) soil models were assigned to the soil cluster. In addition, viscous boundaries were used in the numerical model to simulate the geometric damping and the far-field boundaries. The hammer impact was simulated as a harmonic signal with an amplitude of 5 $\mathrm{MPa}$, a phase of zero degree and a frequency of $50 \mathrm{~Hz}$ similar to what was reported in PLAXIS (2017).

In numerical simulations, loose and dense Baskarp sands were used as the soil deposit. As explained by Elmi Anaraki (2008), Baskarp sand is a uniform sand with a total unit weight of $20 \mathrm{kN} / \mathrm{m}^{3}$, an initial void ratio of 0.83 and 0.65 representing the loose and dense conditions, respectively. The soil properties assigned for Hardening Soil and Hypoplastic soil models were selected based on Dung (2009) and Elmi Anaraki (2008) studies, while the equivalent MohrCoulomb soil model properties were obtained from Aghayarzadeh et al. (2018), who correlated the results of a drained triaxial test using the soil test facility defined in PLAXIS software. The soil properties corresponding to each soil model and interface parameters used in numerical simulation are summarised in Tables 1 to 4 .

It should be noted that in order to simulate the interaction between the pile and soil, appropriate interface elements were considered. In all soil models, the interface strength and deformation parameters were assumed to be correlated to the surrounding soil parameters without consideration of any reduction factor for the sake of simplicity. In other words, for Mohr-Coulomb and Hardening Soil models the interface strength reduction factor $\left(\mathrm{R}_{\text {int }}\right)$ was assumed to be equal to one and for the Hypoplastic model, according to PLAXIS (2017), the interface parameters defined in Table 4 were considered. According to ASTM D 4945 (2010), the strain gauge and the accelerometer during the dynamic load testing should be mounted at least 1.5D ( $\mathrm{D}$ is diameter of pile) below the pile head. In this study, force and velocity traces were recorded at 2D distance below the pile head. An illustration of the finite element model used in analysis is shown in Figure 1a. As shown in Figure 1b, half sine load with a dynamic time interval of 0.01 s (i.e. $50 \mathrm{~Hz}$ as mentioned earlier) was applied on the pile head to simulate the hammer load.

Table 1. Baskarp sand properties for Hypoplastic soil model with Intergranular Strain (after Dung 2009)

\begin{tabular}{ll}
\hline Parameters & $\begin{array}{l}\text { Hypoplastic model with } \\
\text { intergranular strain }\end{array}$ \\
\hline$\phi_{c}($ degree $)$ & 30 \\
$h_{s}(\mathrm{MPa})$ & 4000 \\
$\mathrm{n}$ & 0.42 \\
$e_{d 0}$ & 0.548 \\
$e_{c 0}$ & 0.929 \\
$e_{i 0}$ & 1.08 \\
$\alpha$ & 0.12 \\
$\beta$ & 0.96 \\
$m_{T}$ & 2 \\
$m_{R}$ & 5 \\
$R_{\max }$ & 0.0001 \\
$\beta_{r}$ & 1 \\
$\chi$ & 2 \\
\hline
\end{tabular}

Table 2. Baskarp sand properties for Hardening Soil model (after Dung 2009)

\begin{tabular}{lll}
\hline Parameters & Dense & Loose \\
\hline$E_{50}^{\text {ref }}(\mathrm{MPa})$ & 40.5 & 31 \\
$E_{\text {oed }}^{\text {ref }}(\mathrm{MPa})$ & 50 & 33 \\
$E_{\text {ur }}^{\text {ref }}(\mathrm{MPa})$ & 121.5 & 93 \\
$\phi($ degrees $)$ & 37 & 31.3 \\
$\psi($ degrees $)$ & 9 & 2 \\
$\mathrm{~m}$ & 0.5 & 0.5 \\
$v_{\text {ur }}$ & 0.2 & 0.2 \\
$p^{\text {ref }}(\mathrm{kPa})$ & 100 & 100 \\
\hline
\end{tabular}

Table 3. Baskarp sand properties for Mohr-Coulomb soil model including both tangent and secant soil modulus (after Aghayarzadeh et al. 2018)

\begin{tabular}{lll}
\hline Parameters & Dense & Loose \\
\hline $\mathrm{E}_{\mathrm{i}}(\mathrm{MPa})$ & 60 & 45 \\
$\mathrm{E}_{50}(\mathrm{MPa})$ & 33 & 24.75 \\
$v$ & 0.35 & 0.25 \\
$\phi$ (degree) & 37 & 31.3 \\
$\psi$ (degree) & 9 & 2 \\
\hline
\end{tabular}

The first version of the Hypoplastic constitutive law was proposed by Kolymbas (1985), describing the stress-strain behaviour of granular materials in a rate form. The Hypoplastic model can successfully predict the soil behaviour in the medium to large strain ranges. However, in the small strain range and upon cyclic loading it cannot predict the high quasielastic soil stiffness accurately. To overcome this problem, an extension of the Hypoplastic equation by 
considering an additional state variable, termed 'Intergranular Strain (IGS)", was proposed by Niemunis \& Herle (1997) to determine the direction of the previous loading. In fact, the Intergranular Strain concept enables to model small-strain-stiffness effects in Hypoplasticity and therefore adopted in this study.

Table 4. Interface parameters for Hypoplastic soil model used in numerical modelling (after Aghayarzadeh et al. 2018)

\begin{tabular}{lll}
\hline Parameters & Dense & Loose \\
\hline$E_{\text {oed }}^{\text {ref }}(\mathrm{MPa})$ & 50 & 33 \\
$c_{\text {ref }}^{\prime}(\mathrm{kPa})$ & 0.1 & 0.1 \\
$\phi^{\prime}($ degree $)$ & 37 & 31.3 \\
$\psi$ (degree) & 9 & 2 \\
UD-Power & 0 & 0 \\
$\mathrm{UD}-P^{\text {ref }}(\mathrm{kPa})$ & 100 & 100 \\
\hline
\end{tabular}

\section{PILE DRIVING SIMULATION}

As explained by Masouleh \& Fakharian (2008), one of the important advantages of pile driving and pile load testing simulation in finite element and finite difference software is that the radiation or geometric damping is automatically considered in numerical modelling. In fact, the travelling compressive or tensile wave along the pile shaft causes a relative displacement between pile and soil, which results in generation of shear wave in the adjacent soil that can propagate radially. For evaluating the radiation damping effect, in this study shear stress variations with time at a depth of $4 \mathrm{~m}$ and at different distances from the pile axis (i.e. 1, 3, 6 and $9 \mathrm{~m}$ ) in both dense sand and loose sand were recorded (Figure 2). Figure 2 represents a rapid reduction of shear stress wave amplitude with distance from the pile skin, such that near the vertical boundaries, it is practically zero for both dense and loose sand. This finding not only confirms the soil inertia or radiation damping effect in finite element modelling, but also proves that the viscous boundary has been regarded far enough to prevent the wave reflection in the model.

During the pile load testing and pile driving, the pile head displacement is one of the most important factors that should be taken into account. In this paper the pile head displacement of concrete pile driven into the saturated dense and loose sand using three constitutive soil models are obtained and compared to each other, as illustrated in Figure 3.

Referring to Figure 3, it is evident that driving a pile into dense sand induces less displacement compared to loose sand. All employed constitutive soil models including Mohr-Coulomb, Hardening Soil and Hypoplastic with Intergranular Strain (IGS) delivered reasonably a similar trend. It is worth mentioning that in the study conducted by Aghayarzadeh et al. (2018) related to simulation of the static load testing, $\mathrm{E}_{50}$ (the secant modulus) was used in Mohr-
Coulomb model and it showed a reasonable correlation with other soil models, hence in this study MohrCoulomb model was used embracing this elastic modulus. However, it can be seen that using Hypoplastic soil model without activating the Intergranular Strain generates an increase in the observed displacement of pile head with time. Since the stress wave induced by the hammer impact dissipates, then it is not expected that the displacement to increase significantly. It is evident that HP model with IGS activation yields much less strain compared to the case when the IGS is not applied. This is mainly attributed to the fact that IGS concept simulates the small strain behaviour which is dominant during the pile driving.

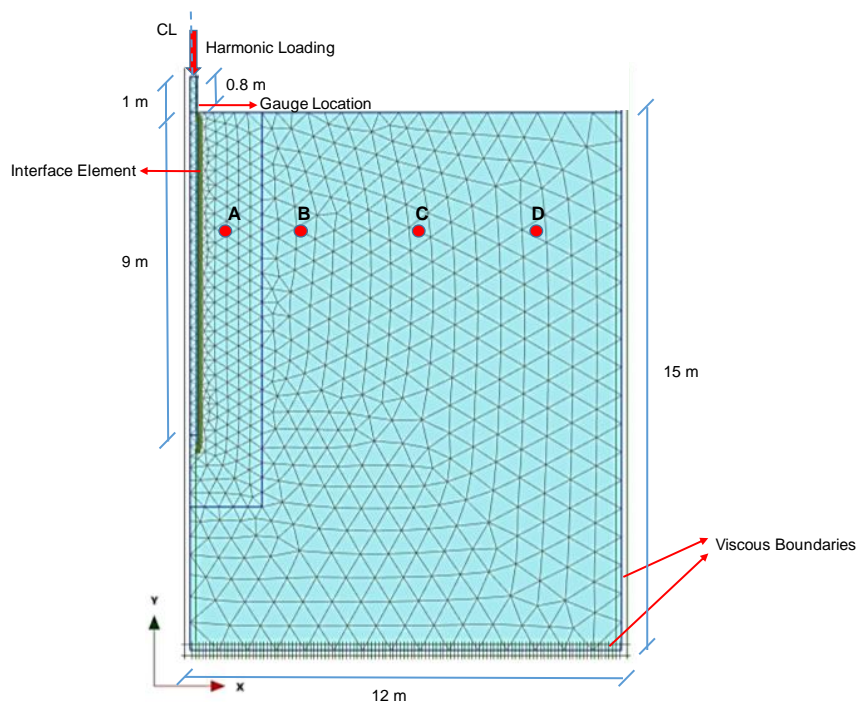

(a)

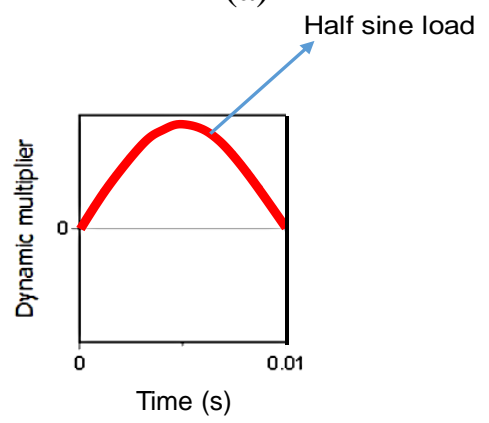

(b)

Figure 1. (a) Finite element model of the pile and the adjacent ground with the corresponding generated mesh and points $\mathrm{A}, \mathrm{B}$, $C$ and $D$ and their corresponding radiuses $r_{A}=1 \mathrm{~m}, r_{B}=3 \mathrm{~m}, r_{c}=6 \mathrm{~m}$ and $\mathrm{r}_{\mathrm{D}}=9 \mathrm{~m}$ (b) applied harmonic load

Generally, when a sudden axial force is applied on a pile, a stress wave is generated, which travels away from the point of force application. As long as stress waves at the gauge location, travel in only one direction and no reflections arrive at this point, the force in the pile is proportional to the velocity of particle motion; known as proportionality theory. The proportionality between these two curves (i.e. force and velocity versus time curves) is destroyed as soon as waves, caused by the soil resistance forces at the pile boundaries, reach the top of pile. The concept of one 
dimensional wave propagation generated by a hammer impact, comprising of induced compressive wave and reflected wave as a result of the soil resistance, is schematically shown in Figure 4. The proportionality relationship can be written as:

$$
F(t)=Z v(t)
$$

$v(\mathrm{t})=$ the velocity of particle motion (downward positive) at the point under consideration $(\mathrm{m} / \mathrm{s})$

$\mathrm{F}(\mathrm{t})=$ the force (compression positive) at the point of interest where velocity is determined $(\mathrm{kN})$

$Z=E A / c=$ impedance or the proportionality coefficient between force and velocity (kN.s/m)

$\mathrm{c}=$ the velocity of propagation of the stress wave $(\mathrm{m} / \mathrm{s})$, which in concrete piles is regarded as approximately $3600 \mathrm{~m} / \mathrm{s}$

$\mathrm{A}=$ the pile cross-sectional area of pile $\left(\mathrm{m}^{2}\right)$

$\mathrm{E}=$ the modulus of elasticity of pile $(\mathrm{kPa})$

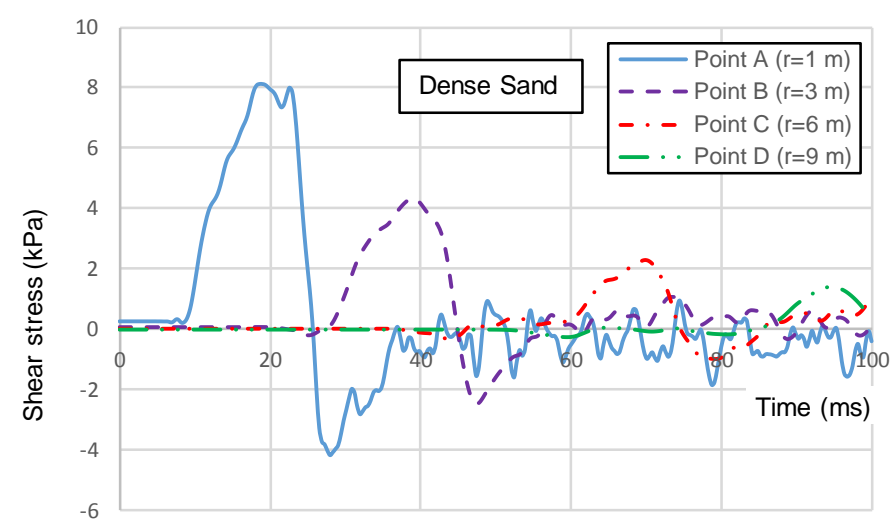

(a)

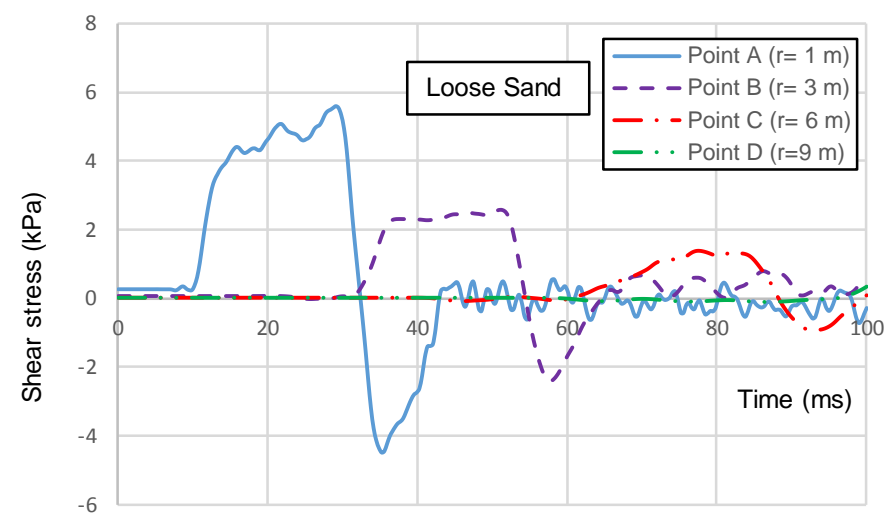

(b)

Figure 2. Variation of shear stress in soil at different distances from pile shaft (a) dense sand (b) loose sand (Hardening Soil model)

The recorded velocity at the gauge location $(v(t))$ multiplied by the impedance $(Z)$ of the pile is shown in Figure 5. As shown in Figure 5, velocity traces predicted by different soil models have a reasonable agreement. However, Hypoplastic model without considering IGS could not simulate the dissipation of velocity with time. As explained earlier, due to the small strain behaviour observed during driving by incorporating the Intergranular Strain (IGS), a more reasonable response and predictions are achieved.

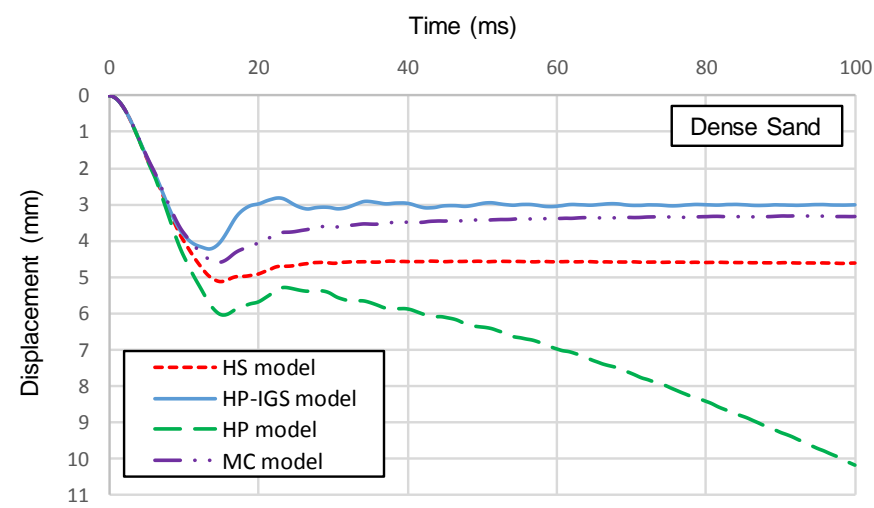

(a)

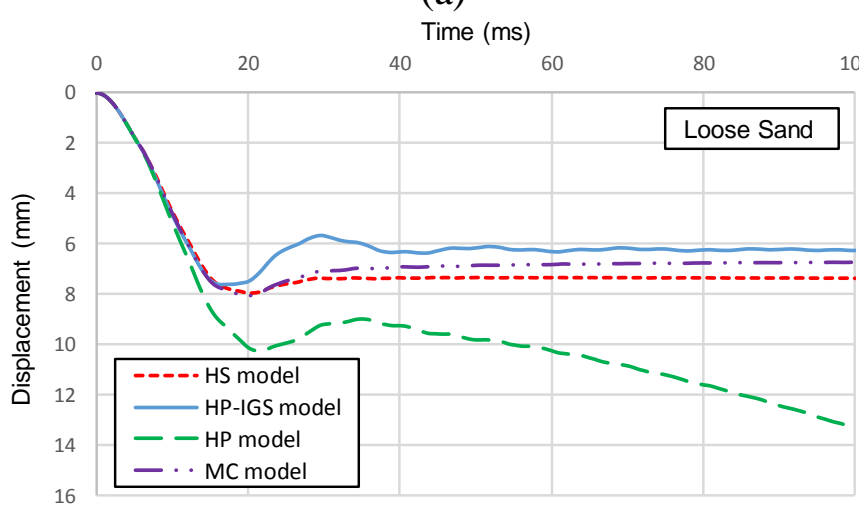

(b)

Figure 3. Pile head displacement (a) dense sand (b) loose sand

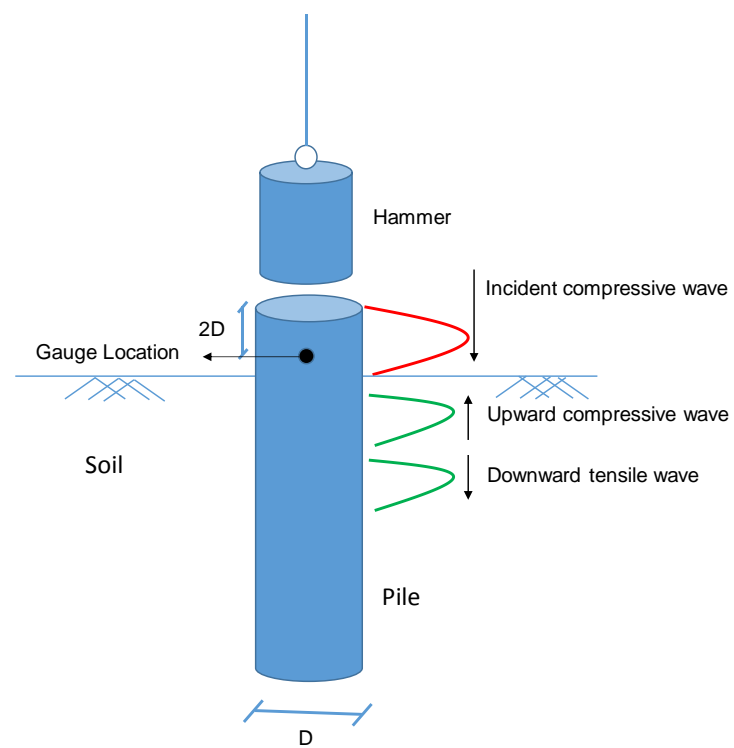

Figure 4. One dimensional wave propagation caused by hammer impact

Force and velocity $\times$ impedance traces, recorded at the gauge location, are compared in Figure 6. Referring to Equation (1), it is expected to observe a reasonable correlation between force and velocity $\times$ impedance traces particularly before the first peak of both curves. However, as it is illustrated in Figure 6, discapancies are observed. This is mainly attributed 
to the long stress wave period assumed for the hammer impact which causes overlapping between the incident and reflected waves within the observation time. For evaluating this wave overlapping effect, the frequency of loading increased from $50 \mathrm{~Hz}$ to $250 \mathrm{~Hz}$. As shown in Figure 7, the half sine period or impact time decreased to $0.002 \mathrm{~s}$. The corresponding force and velocity $\times$ impedance traces were recorded and shown in Figure 8.

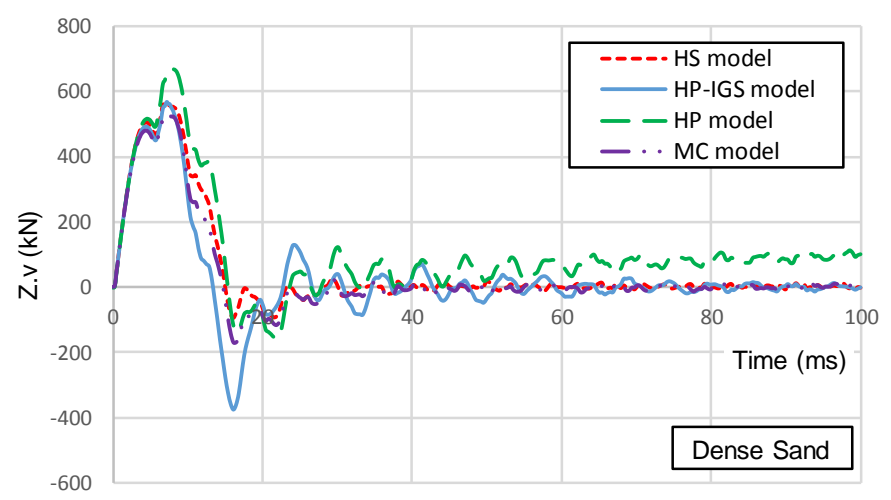

(a)

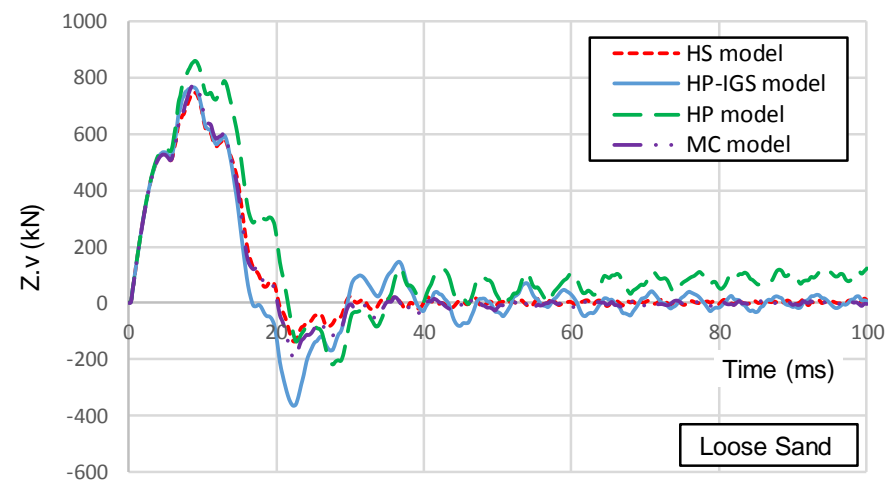

(b)

Figure 5. Impedance $\times$ Velocity variation with time, recorded at the gauge location for (a) dense sand (b) loose sand

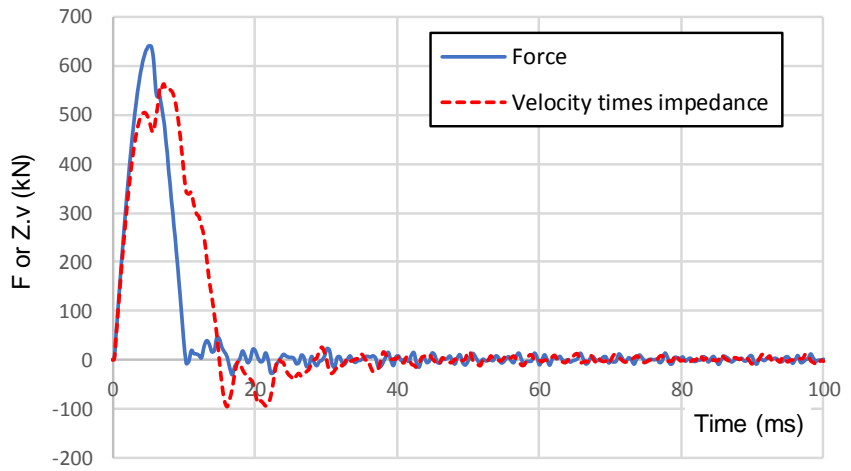

Figure 6 . Velocity $\times$ impedance and force traces, recorded at the gauge location using Hardening Soil model for dense sand by applying harmonic loading with a frequency of $50 \mathrm{~Hz}$

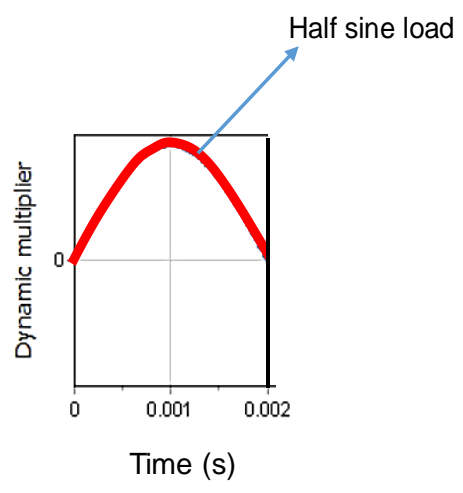

Figure 7. Applied harmonic load with a frequency of $250 \mathrm{~Hz}$

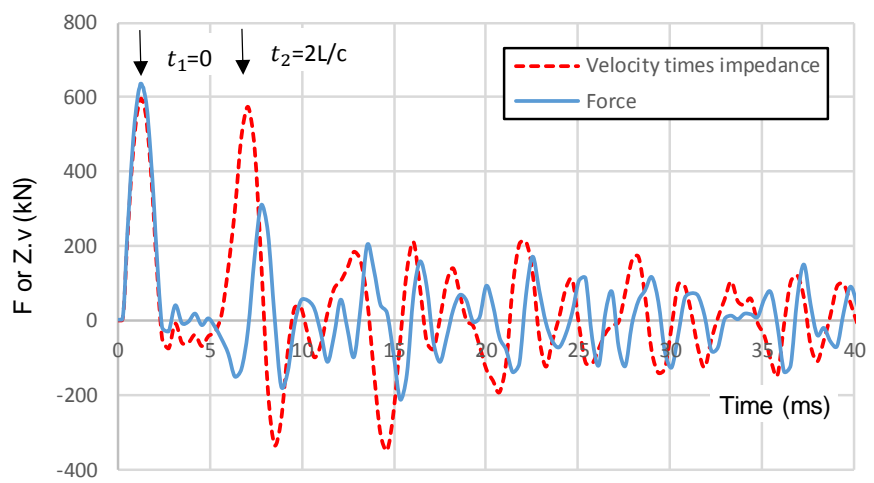

Figure 8 . Velocity $\times$ impedance and force traces, recorded at the gauge location using Hardening Soil model for dense sand by applying a harmonic load with a frequency of $250 \mathrm{~Hz}$

As shown in Figure 8, by increasing the impact load frequency to $250 \mathrm{~Hz}$, both force and velocity traces show reasonable correlations before the first peak (corresponding to $t_{1}$ ) since decreasing the impact time causes a decrease in the length of the induced compressive wave. As explained by Lowery et al. (1969), when the compressive stress wave reaches the toe of the pile, it will be reflected back up the pile in some manner depending on the soil resistance. If the toe of the pile is experiencing slight or no resistance from the soil, it will be reflected back up the pile as a tensile stress wave and these two waves may overlap at the certain points. On the other hand, if the soil is hard or very firm at the pile toe, the initial compressive stress wave traveling down the pile will be reflected back up the pile also as a compressive stress wave and again these two stress waves may overlap. In the case that toe is experiencing slight resistance and pile length is short compared to the length of the stress wave, the reflected tensile stress wave overlaps with the initial compressive stress wave coming down the pile. Since the net stress at any point is the algebraic sum of the two, they tend to cancel each other at the toe and hence little or no reflected tensile stress wave will occur. In addition, the length of the stress wave induced by ram impact can be calculated by the following equation:

$$
L_{s}=\mathrm{ct}
$$


where $L_{S}=$ the length of stress wave (m)

$t_{s}=$ the time of ram contact (impact time) (s)

$\mathrm{c}=$ the velocity of stress wave $(\mathrm{m} / \mathrm{s})$

By applying a load with a frequency of $50 \mathrm{~Hz}$, the contact time of hammer and pile is regarded as 0.01 $\mathrm{s}$, as shown in Figure $1 \mathrm{~b}$, generating a compressive stress wave with $36 \mathrm{~m}$ length that is considerably longer than pile length. However, when the frequency of loading increases to $250 \mathrm{~Hz}$, the contact time of the hammer and pile decreases to $0.002 \mathrm{~s}$ while the length of corresponding stress wave would be $7.2 \mathrm{~m}$, which is shorter than the pile length.

Referring to Figure 8, at time $2 \mathrm{~L} / \mathrm{c}$ (the time corresponding to travelling down the wave and reflecting from pile toe to the gauge location) the force trace is negative and velocity $\times$ impedance is positive, which resembles the reflection of tensile stesss from the pile toe. In reality, the pile tip is embedded in a sandy deposit having a high densification potential during the driving process. On the basis of an analytical study conducted by Yang (2006), the influence zone of an axially loaded pile in clean sand and compacted silty sand can extend to 3.5D-5.5D and 1.5D-3D (D is the pile diameter) below the pile toe, respectively. However, in this study the the properties of soil below the toe were not changed and were basically assumed as the initial insitu conditions. Thus, the pile toe showed a rather low resistance against penetration causing the reflection of tensile stresses.

\section{FURTHER ASSESSMENT OF HYPOPLASTIC MODEL FOR PILE DRIVING}

\subsection{Parametric study}

In this section, the influence of different paramters, defined in the Hypoplastic model with the Intergranular Strain concept on the obtanied pile head displacement during the pile driving is evaluated. As reported by Aghayarzadeh et al. (2018), among the Hypoplastic model parameters, the granular hardness $\left(h_{s}\right)$ showed the least impact, whereas the critical friction angle $\left(\varphi_{c}\right)$ indicated the most significant influence on the load-displacement curve, obtained during the simulation of static load testing. Herein, the effect of these two parameters are evaluated on the recorded pile head displacement during pile driving. To achieve this aim, the critical friction angle increased by $30 \%$, while other Hypoplastic factors remained unchanged. As shown in Figure 9a, similar to the observed results during static load test, increasing the critical friction angle shows a considerable effect on the recorded displacement. Referring to Figure 9b, increasing the granular stiffness $\left(\mathrm{h}_{\mathrm{s}}\right)$ by up to $30 \%$ does not show any notable influence on the predicted displacement.
The sensisitivity of the simulated response of the recorded pile head displacement during driving to the varaition of Intergranular Strain paramters are shown in Figure 10. The Intergranular Strain includes five model parameters:

$m_{R}=$ paramter controlling the initial (very small strain) shear modulus upon 180 degree strain path reversal and in the initial loading

$m_{T}=$ parameter controlling the initial shear modulus upon 90 degree strain path reversal

$R=$ the size of the elastic range

$\beta_{r}$ and $\chi=$ parameters controling the rate of degradation of the stiffness with strain

Reffering to Mašín (2015) in IGS extension, the stifness evolution is as follows:

$$
\begin{array}{ll}
E=m_{R} E_{0} & \varepsilon<R \\
E=E_{0}+E_{0}\left(m_{R}-1\right)\left(1-\rho^{\chi}\right) & \varepsilon>R
\end{array}
$$

Where $\rho$ is the magnitude of the Intergranular Strain rate and $E_{0}$ is the initial tangent modulus.

However as explained by Dung (2009), three of IGS parameters including $m_{T}, m_{R}$ and $\mathrm{R}$ can be usually taken as constants. Therefore, in this study, only the variation of two parameters, namely $\beta_{\mathrm{r}}$ and $\chi$, controlling the rate of degradation of the stiffness with strain, are considered and investigated.

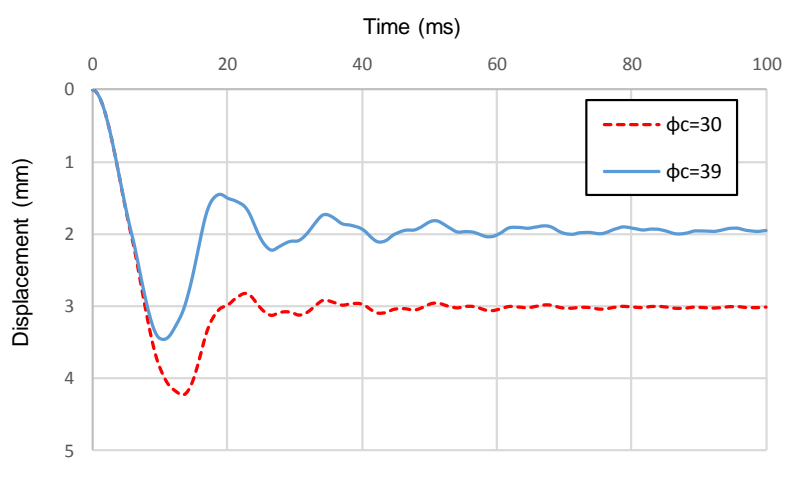

(a)

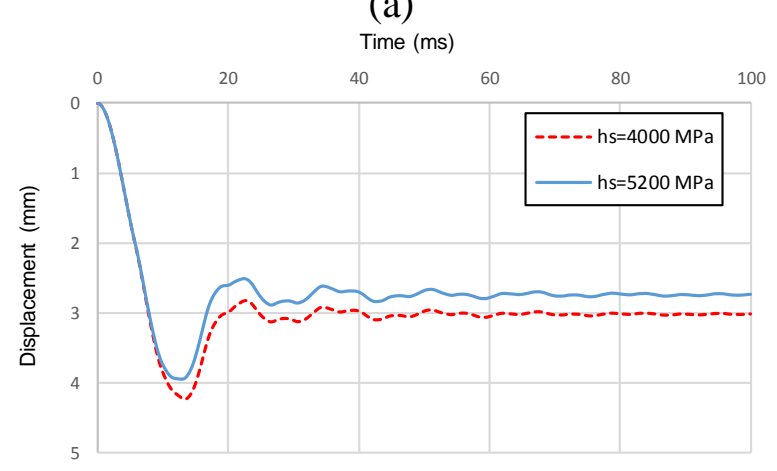

(b)

Figure 9. Influence of hypoplastic model parameters on the measured pile head displacement during the pile driving in dense sand (a) critical friction angle (b) granular hardness

In fact both parameters $\beta_{\mathrm{r}}$ and $\chi$ control the shape of stifness degradation curves (Mašín 2015, Niemunis \& Herle 1997). Referring to Figure 10, it can be 
inferred that by increasing $\chi$ and decreasing $\beta_{\mathrm{r}}$ the elastic range of stiffness degradation curves increases, and, hence pile head displacement shows more elastic deformation.

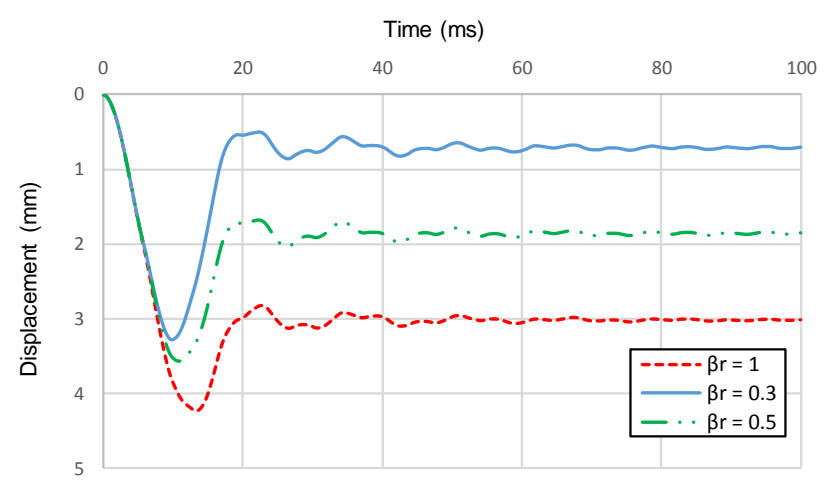

(a)

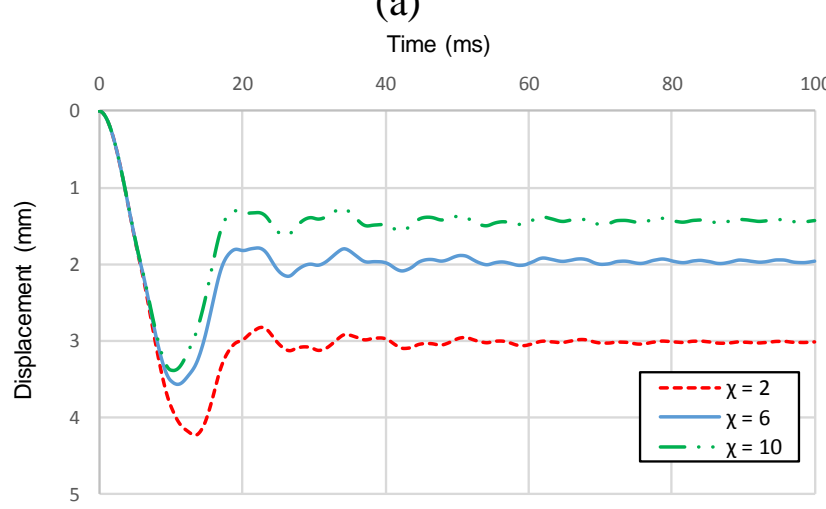

(b)

Figure 10. Influence of Intergranular Strain parameters defined in Hypoplastic model on the measured pile head displacement during the pile driving in dense sand (a) $\beta_{\mathrm{r}}$ and (b) $\chi$

\subsection{Intergranular Strain tensors}

In this section in order to assess the behaviour of piles during the driving and the extent to which Intergranular Strain (IGS) can impact the predictions, the pile was simulated in both dense and loose sand using Hypoplastic model with IGS. In fact the behaviour of pile during the driving consists of loading and unloading stages ( $\mathrm{Ng}$ 2011, Ng et al. 2013). Herein the normalized Intergranular Strain tensors are depicted in Figures 11 and 12 for dense sand and loose sand at the end of the driving (unloading conditions), respectively. According to Mašın (2010) the normalized length of the Intergranular Strain tensor varies between 0 and 1 , corresponding to the soil being inside the elastic range and swept-out of the small-strain memory, respectively. In other words, the normalized length of the Intergranular Strain tensor demonstrates how the small-strain stiffness is activated in different parts of the modelled geometry. In the case of the normalized length of the Intergranular Strain being equal to 1 , the soil behaviour is governed by the basic Hypoplastic model. Figures 11 and 12 show that at the end of driving in the vicinity of the pile, the predicted values for normalized length of the Intergranular Strain tensor are very low and at these locations the soil elements behave elastically and show small strain behaviour. In addition, it is observed that dense sand shows more elastic behaviour compared to loose sand. This clearly indicates the presence of the small strain behaviour of soil around the pile during the propagation and dissipation of the induced wave in the pile.
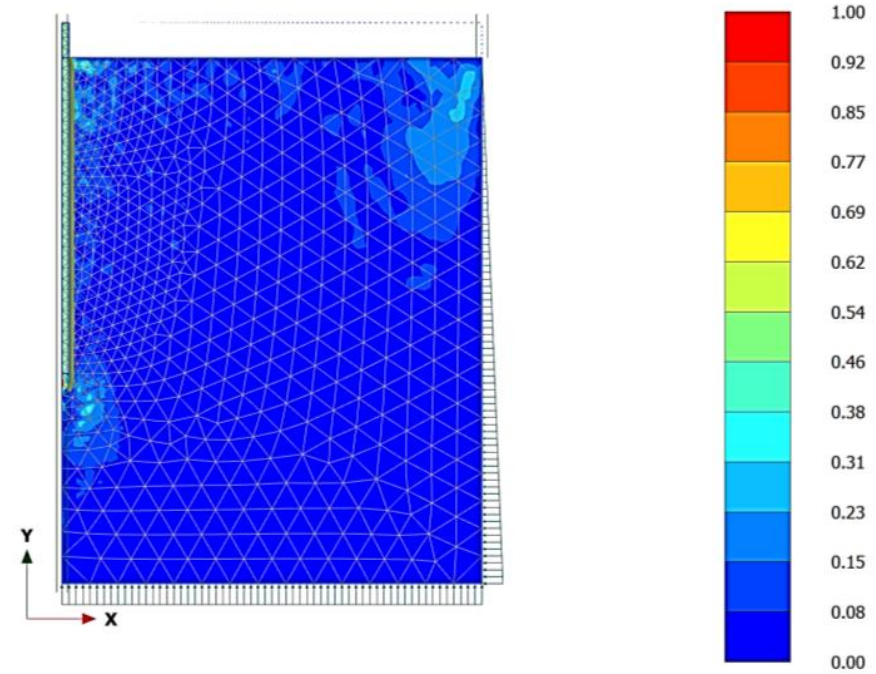

Figure 11. Concrete pile driving- normalised Intergranular Strain tensor for dense sand
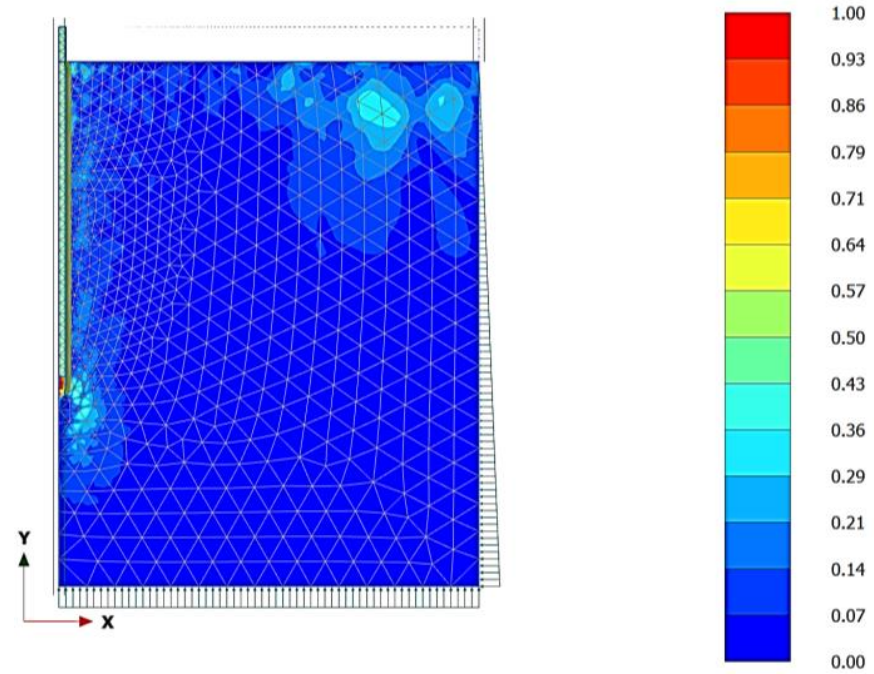

Figure 12. Concrete pile driving- normalised Intergranular Strain tensor for loose sand

\section{CONCLUSIONS}

In this study, it has been observed that the three target constitutive soil models, including Mohr-Coulomb, hardening soil and Hypoplastic with Intergranular Strain soil models, can yield similar trends in terms of the pile head displacement and the recorded velocity at the gauge location during pile driving process. 
However, introducing the Intergranular Strain concept provides more reasonable predictions and can accumulate significantly less strains.

In addition, the influence of frequency on pile driving was evaluated in this study. The results showed that by increasing the hammer impact time, the length of the induced stress wave increases and therefore induced and reflected waves may overlap considerably. This finding correlates well with the fact that in short piles (i.e. the length of the pile is considerably smaller than the stress wave length), the downward and upward travelling waves can overlap before the peak force or velocity at the gauge location is reached. Moreover, parametric study on Intergranular Strain was conducted on two key parameters of Hypoplastic model, including the critical friction angle and the granular hardness. It was found that the variation of critical friction angle impacted the predicted pile performance during driving significantly, whereas the effect of the granular hardness variation was negligible. Furthermore, parameters affecting the rate of degradation of the stiffness with strain defined in intergranular strain (IGS) concept could change the elastic range of soil. Finally, by evaluating the normalised Intergranualr tensors it was shown that by introducing the IGS in the model the soil in the vicinity of pile would indicate the small strain behaviour during the unloading stage as expected.

\section{REFERNCES}

Aghayarzadeh, M., Khabbaz, H. \& Fatahi, B. 2018. Evaluation of concrete bored piles behaviour in saturated loose and dense sand during the static load testing. 5th GeoChina International Conference. HangZhou, China (accepted).

ASTM 2010. Standard test method for high-strain dynamic testing of piles. D 4945-08. Philadelphia: ASTM.

Dung, P. H. 2009. Modelling of installation effect of driven piles by hypoplasticity. Master of Science thesis, Delft University of Technology.

Elmi Anaraki, K. 2008. Hypoplasticity investigated. Master of Science thesis, Delft University of Technology.

Fakharian, K. \& Hosseinzadeh, A. I. 2011. Pile driving experiences in Persian Gulf calcareous sands. Frontiers in Offshore Geotechnics II. London: Taylor \& Francis Group.

Fakharian, K., Masouleh, S. F. \& Mohammadlou, A. S. 2014. Comparison of end-of-drive and restrike signal matching analysis for a real case using continuum numerical modelling. Soils and Foundations, 54, 155-167.

Fatahi, B., Basack, S., Ryan, P., Zhou, W.-H. \& Khabbaz, H. 2014. Performance of laterally loaded piles considering soil and interface parameters. Geomechanics and Engineering, 11, 501-516.

Fatahi, B., Van Nguyen, Q., Xu, R. \& Sun, W.-j. 2018. ThreeDimensional response of neighboring buildings sitting on pile foundations to seismic pounding. International Journal of Geomechanics, 18, 04018007.

Goble, G. \& Rausche, F. 1970. Pile load test by impact driving. Highway Research Board Annual Meeting, Washington, DC.
Goble, G. G., Scanlan, R. \& Tomko, J. J. 1967. Dynamic studies on the bearing capacity of piles. Ohio Highway Engineering Conference Proceedings.

Hokmabadi, A. S. \& Fatahi, B. 2016. Influence of foundation type on seismic performance of buildings considering soilstructure interaction. International Journal of Structural Stability and Dynamics, 16, 1550043.

Kolymbas, D. 1985. A generalized hypoelastic constitutive law. Proc. XI Int. Conf. Soil Mechanics and Foundation Engineering.

Lowery, L. L., Hirsch, T., Edwards, T. C., Coyle, H. M. \& Samson, C. 1969. Pile driving analysis: State of the art, Texas Transportation Institute, Texas A \& M University.

Mabsout, M. E., Reese, L. C. \& Tassoulas, J. L. 1995. Study of pile driving by finite-element method. Journal of geotechnical engineering, 121, 535-543.

Mabsout, M. E. \& Tassoulas, J. L. 1994. A finite element model for the simulation of pile driving. International Journal for numerical methods in Engineering, 37, 257-278.

Mašin, D. 2010. PLAXIS implementation of Hypoplasticity.

Mašín, D. 2015. Hypoplasticity for practical applications. $P h D$ course on hypoplasticity. Zhejiang University.

Masouleh, S. F. \& Fakharian, K. 2008. Application of a continuum numerical model for pile driving analysis and comparison with a real case. Computers and Geotechnics, 35, 406-418.

$\mathrm{Ng}, \mathrm{K} . \mathrm{W} .2011$. Pile setup, dynamic construction control, and load and resistance factor design of vertically-loaded steel H-Piles, Iowa State University.

$\mathrm{Ng}, \mathrm{K}$. W. \& Sritharan, S. 2013. Improving dynamic soil parameters and advancing the pile signal matching technique. Computers and Geotechnics, 54, 166-174.

Niemunis, A. \& Herle, I. 1997. Hypoplastic model for cohesionless soils with elastic strain range. Mechanics of Cohesive-frictional Materials, 2, 279-299.

PLAXIS, B. 2017. Plaxis 2D Version. 2017. Reference Manual. Delft, The Netherlands.

Rausch, F., Moses, F. \& Goble, G. G. 1972. Soil resistance predictions from pile dynamics. Journal of the soil mechanics and foundations division, 98, 917-937.

Yang, J. 2006. Influence zone for end bearing of piles in sand. Journal of geotechnical and geoenvironmental engineering, $132,1229-1237$. 